\title{
ELASTO-PLASTICITY OF UNSATURATED SOILS: LABORATORY TEST RESULTS ON A REMOULDED SILT
}

\author{
Françoise Geiseri), Lyesse Laloui ${ }^{\mathrm{i})}$ and Laurent Vulliet ${ }^{\mathrm{i})}$
}

\begin{abstract}
Current models of the elasto-plastic behaviour of unsaturated soils contain important underlying assumptions that have not been tested due to a lack of adequate experimental data. To address this issue, the objective of this paper is to provide a comprehensive set of experimental data. An extensive experimental program has been performed on a remoulded unsaturated silt. To characterise its elasto-plastic behaviour, samples were taken through various stress paths, including wetting, drying and compression. Experimental results were analysed to provide (1) evidence of suction-induced preconsolidation; (2) dependence of cohesion and shear strength at failure on suction; (3) stiffness in relation to suction and (4) uniqueness of the critical state line.
\end{abstract}

Key words: deformation, laboratory tests, partially saturated soil, plasticity, shear strength, silts (IGC: D5/D6)

\section{INTRODUCTION}

Experimental data showing all aspects of the behaviour of a particular unsaturated soil are scarce. This is mainly due to the many (well-known) experimental difficulties and the time-consuming nature of testing unsaturated soils. Earlier research work studied the shear strength (Fredlund et al., 1978; Escario and Saez, 1986) and isotropic compression of unsaturated soil at different initial suction values (Matyas and Radhakrishna, 1968) separately. More recently, significant progress has been made in an attempt to better understand the link between shear strength and volume change, and to characterise it within a single framework. In these works the experimental results examined the stress-strain relationship, including volume measurement by e.g. Alonso et al. (1990), Wheeler and Sivakumar (1995) both on compacted kaolin, Cui and Delage (1996) on Jossigny silt, and finally, Maâtouk et al. (1995) on Trois-Rivières silt. However, none of these works addressed the relevance of the suction value, $s_{\mathrm{e}}$, at which air enters into the pores of soils. If the suction applied to the soil is less than this air-entry value, $s_{\mathrm{e}}$, the behaviour of the soil can accurately be interpreted using the standard effective stress concept (Fleureau and Indarto, 1993; Fleureau et al., 1995; Karube and Kawai, 2001; Kohgo et al., 1993). When the suction value exceeds the air-entry value, however, two stress state variables may be necessary for a complete description of the soil. This dependency of the stress-strain relationship on suction is further examined in this paper using experimental data obtained on Sion silt.

Other researches have examined the drying-wetting behaviour of soils at a given external loading pressure (e.g. Croney and Coleman, 1954; Blight, 1966; Biarez et al., 1988; Zerhouni, 1991; Fleureau et al., 1993). On a first-time drying path the saturated sample is initially very compressible and then, beyond a suction close to $S_{\mathrm{e}}$, it becomes less compressible, showing a quasi-reversible behaviour. These observations do not correspond with the assumptions made in the elasto-plastic framework proposed by Alonso et al. in 1990 and extended by other authors (Wheeler and Sivakumar, 1995; Wheeler, 1996). In this widely-used model, it is assumed that the suction effect is similar to the effect of a mean effective stress under isotropic loading conditions (i.e. with initial elastic behaviour followed by an elasto-plastic response).

In this paper we contribute to a complete experimental knowledge of the stress-strain relationship of unsaturated soils by examing the behaviour of remoulded Sion silt. Samples were subjected to various stress paths including: (i) isotropic compression at controlled suction and (ii) drying-wetting by means of increasing and decreasing the suction at a controlled external pressure. Both of these were followed by shearing the sample to critical state.

As in previous research we assume the behaviour of unsaturated soils can be fully described by two stress state variables. It has been shown by Fredlund and Morgenstern (1977) that the total stress, the pore air pressure and the pore water pressure can be expressed in any two independent stress combinations in order to characterise the mechanical behaviour of unsaturated soils. Typically, the net stress and the matric suction are chosen as state variables. In this paper, however, the results are also analysed using the combination of the "saturated effective" stress and the matric suction. Such a combination

i) Soil Mechanics Laboratory, Swiss Federal Institute of Technology, ENAC-EPFL, Switzerland (lyesse.laloui@epfl.ch). The manuscript for this paper was received for review on January 11, 2005; approved on May 29, 2006.

Written discussions on this paper should be submitted before May 1, 2007 to the Japanese Geotechnical Society, 4-38-2, Sengoku, Bunkyo-ku, Tokyo 112-0011, Japan. Upon request the closing date may be extended one month. 


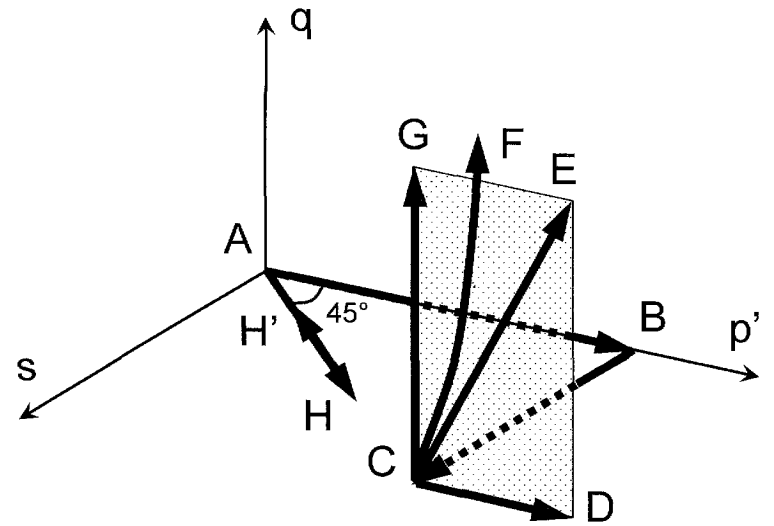

Fig. 1. Hydro-mechanical stress paths followed in this study

allows continuity in the modelling of the saturated and unsaturated states.

\section{MATERIAL PREPARATION}

The soil examined in the research reported here is a sandy silt (USCS classification: CL-ML) from the region of Sion (Switzerland). The density of solid particles is $\rho_{\mathrm{s}}=2.794 \mathrm{Kg} / \mathrm{m}^{3}$. The index properties of the soil are: $w_{\mathrm{L}}=25.4 \%, \quad w_{\mathrm{P}}=16.7 \%, I_{\mathrm{P}}=8.7 \%$. The grain size distribution is $8 \%$ clay, $72 \%$ silt and $20 \%$ sand. Special care was taken in sample preparation to ensure the reproducibility of the initial state. The sample preparation procedure consisted of mixing a known mass of dry soil with de-aired and demineralised water to an initial water content $w=1.5 \quad w_{\mathrm{L}}$. This water content was assumed large enough to produce a slurry that has no internal structure. To remove air bubbles trapped in the slurry, the soil was vibrated. It was then placed inside a hermetically closed box for 24 hours. The initial void ratio $e_{0}$ at the slurry state varied between 0.9 and 1 . For the triaxial tests the samples were prepared in a moulding tube ( $K_{0}$ condition) subject to a vertical consolidation stress of $100 \mathrm{kPa}$. This led to samples having initial void ratios between 0.69 and 0.76 , and water content between $24.8 \%$ and $27.6 \%$.

\section{TESTING PROGRAMME AND PROCEDURES}

The saturated behaviour of the Sion silt was first characterised. A total of 15 tests (on 89 samples) in the pressure plate apparatus and 44 saturated and 30 unsaturated triaxial tests were performed using different stress paths (see Fig. 1). In the following, a compression path represents a path obtained by applying a total external stress $\sigma_{1}$ or $\sigma_{3}$ (axial or lateral stress, respectively) at constant suction and a drying-wetting path corresponds to a path obtained internally by modifying either $u_{\mathrm{a}}$, the pore air pressure or $u_{\mathrm{w}}$, the pore water pressure. We will later define the mean total pressure, $p=(1 / 3)\left(\sigma_{1}+2 \sigma_{3}\right)$, the mean effective pressure, $p^{\prime}=p-u_{\mathrm{w}}$, and the mean net pressure, $p^{*}=p-u_{\mathrm{a}}$.

A pressure plate apparatus was used to study the "drying-wetting" paths (Fig. 1, A-H-H'). The sample own weight was assumed to be negligible. The effective pressure $p^{\prime}$ was kept constant and equal to zero. The samples (diameter $40 \mathrm{~mm}$ and height $\sim 9 \mathrm{~mm}$ ) were placed on a saturated high air entry ceramic disc and subjected to a positive air pressure by increasing the cell pressure, while the pore water pressure $u_{\mathrm{w}}$ remained unchanged. In this way, the capillary suction $s$ was equal to the imposed air pressure $u_{\mathrm{a}}$. For each suction level, at least four samples were prepared. When the variation of the water content tends to be negligible, the hydraulic equilibrium is reached (usually after 200 to 1000 hours on drying paths and took significantly longer on wetting paths). Two samples were used to determine the water content and the other two samples were used for volume measurement. To determine the volume change, the samples were removed from the pressure plate and placed for four hours in petroleum in order to fill the air pores. Because petroleum is hydrophobic, it can be assumed that this procedure causes no water volume change in the sample (preliminary observations showed no significant total volume variation at this stage). The total volume was then measured using a picnometer (Lagny, 1996; Geiser, 1999). Details on this technique as well as the accuracy values are available in Peron et al. (2006).

For the triaxial tests, the samples $(50 \mathrm{~mm}$ in diameter, $100 \mathrm{~mm}$ in height) were first consolidated to a given confining pressure, $p^{\prime}$, (Fig. 1, A-B) under saturated conditions. This was assumed to erase the previous one-dimensional loading history of the sample, as the confining pressure was always higher than the equivalent mean effective stress applied during one-dimensional loading. When the consolidation was completed, samples were subjected to drying path (B-C) at constant "saturated effective pressure" $p^{\prime}$ by increasing $u_{\mathrm{a}}$ while maintaining constant total pressure, $p$, and $u_{\mathrm{w}}$. Finally, when equilibrium was reached (usually after one to three weeks), samples were taken through various stress paths: - Path C-D: isotropic compression. This path was obtained by increasing the confining pressure $p$ while keeping both $u_{\mathrm{a}}$ and $u_{\mathrm{w}}$ constant (thus allowing free flow of air and water). Pressure was applied in steps and was maintained until equilibrium was achieved (usually after several days).

- Path C-E: fully drained shearing (see Table 1). This path was achieved by increasing the deviatoric stress $q=\sigma_{1}-\sigma_{3}$ while keeping both $u_{\mathrm{a}}$ and $u_{\mathrm{w}}$ constant. The rate of shearing varied from 0.0012 to $0.0018 \mathrm{~mm} / \mathrm{min}$ (see next paragraph for details). For most tests, unloading-reloading was performed at an axial strain of $\varepsilon_{1}=2 \%$.

- Path C-F: constant water content shearing (see Table 2). In this case the shearing was carried out under water-undrained conditions while maintaining a constant pore air pressure $u_{\mathrm{a}}$, thus allowing air drainage. The pore water pressure $u_{\mathrm{w}}$ was measured during the shearing so that the suction was known. The appropriate shear rate was $0.06 \mathrm{~mm} / \mathrm{min}$ for these tests.

- Path C-G: constant mean effective pressure. This 
Table 1. Unsaturated drained shear tests

\begin{tabular}{|c|c|c|c|c|c|c|c|c|c|}
\hline Test & $\begin{array}{c}\sigma_{3}^{\prime} \\
\mathrm{A}-\mathrm{B}^{*} \\
(\mathrm{kPa}) \\
\end{array}$ & $\begin{array}{l}s=u_{\mathrm{a}} \\
\mathrm{B}-\mathrm{C}^{*} \\
(\mathrm{kPa})\end{array}$ & $\begin{array}{c}\sigma_{3}^{\prime} \\
\mathrm{C}-\mathrm{D} \text { or } \mathrm{C}-\mathrm{G}^{*} \\
(\mathrm{kPa})\end{array}$ & $\Delta q / \Delta p^{\prime}$ & $\begin{array}{l}e_{\text {init }} \\
(-)\end{array}$ & $\begin{array}{c}e_{\text {final }} \\
(-)\end{array}$ & $\begin{array}{l}w_{\text {final }} \\
(\%)\end{array}$ & $\begin{array}{l}S_{\text {rînal }} \\
(\%)\end{array}$ & $s / \sigma_{3}^{\prime}$ \\
\hline NS-D1 & 400 & 100 & 400 & 3 & 0.802 & 0.66 & 15.6 & 66 & 0.25 \\
\hline NS-D2 & 450 & 50 & 450 & 3 & 0.721 & 0.64 & 19.5 & 85 & 0.11 \\
\hline NS-D3ter & 500 & 100 & 500 & 3 & - & 0.66 & 11.6 & 49 & 0.2 \\
\hline NS-D4 & 600 & 100 & 600 & 3 & 0.788 & 0.64 & 16.8 & 83 & 0.17 \\
\hline NS-D5 & 600 & 200 & 600 & 3 & 0.7 & 0.65 & 7.7 & 33 & 0.33 \\
\hline NS-D6 & 500 & 100 & 500 & 3 & 0.70 & 0.66 & 11.4 & 48 & 0.2 \\
\hline NS-D7 & 400 & 100 & 300 & 3 & 0.724 & - & - & - & 0.33 \\
\hline NS-D9 & 400 & 100 & - & $\infty$ & 0.74 & - & - & - & 0.25 \\
\hline NS-D11 & 600 & 50 & 600 & 3 & 0.755 & 0.62 & 20.4 & 91 & 0.08 \\
\hline NS-D12 & 600 & 280 & 600 & 3 & 0.712 & 0.67 & 6.6 & 27 & 0.47 \\
\hline NS-D13 & 600 & 100 & 500 & 3 & 0.712 & 0.63 & 14.1 & 62 & 0.2 \\
\hline
\end{tabular}

* see paths in Fig. 1.

Table 2. Unsaturated constant water content shear tests (path A-B-C$F$ in Fig. 1)

\begin{tabular}{lcclll}
\hline Test & $\begin{array}{c}\left(\sigma_{3}^{\prime}\right)_{\text {init }} \\
\text { A-B and C-E } \\
(\mathrm{kPa})\end{array}$ & $\begin{array}{c}u_{\mathrm{a}} \\
\mathrm{B}-\mathrm{C} \text { and C-E } \\
(\mathrm{kPa})\end{array}$ & $\begin{array}{l}e_{\text {init }} \\
(-)\end{array}$ & $\begin{array}{c}w_{\text {final }} \\
(\%)\end{array}$ & $\left(s / \sigma_{3}^{\prime}\right)_{\text {init }}$ \\
\hline U1 & 200 & 0 & 0.74 & 23 & 0 \\
NS-U1 & 200 & 30 & 0.735 & 21.1 & 0.15 \\
NS-U2 & 200 & 60 & 0.71 & 20.8 & 0.3 \\
\hline U2 & 300 & 0 & 0.71 & 22 & 0 \\
NS-U3 & 300 & 100 & 0.718 & 18.6 & 0.33 \\
NS-U4 & 300 & 200 & 0.738 & 10.6 & 0.66 \\
NS-U5 & 300 & 280 & 0.712 & 8.2 & 0.93 \\
\hline U5 & 1000 & 0 & 0.748 & 20.5 & 0 \\
NS-U6 & 300 & 100 & 0.712 & 17.6 & 0.1 \\
NS-U7 & 300 & 200 & 0.743 & 9.3 & 0.2 \\
NS-U8 & 300 & 280 & 0.712 & 7.6 & 0.28 \\
\hline
\end{tabular}

consisted of increasing the deviatoric stress while keeping both the mean effective pressure and the suction constant.

Cell pressure, air pressure and water pressure were measured using GDS pressure controllers. Suction to the sample was applied or measured using the axis-translation technique (for details see Fredlund and Rahardjo, 1993), using high air-entry ceramic disc with air-entry values of $100,300,500$ and $1500 \mathrm{kPa}$.

\section{Volume Changes}

Measurement of volume changes in triaxial tests is essential when analysing the mechanical behaviour of a soil. In the case of a saturated test, volume change is only due to water exchange and can easily be measured with a burette or a pressure-volume controller. In the case of unsaturated samples, however, sample volume change is related to both water and air volume changes and cannot be measured so readily (Laloui et al., 2006). The air-water volume method has been used in this work for the volume change measurement. In this approach, the volumetric change of the sample is obtained by simply adding the air and water volume changes. Both volume changes are measured using pressure-volume controllers. Very few experimental data exist in the literature for this method. Our tests have shown that temperature and atmospheric pressure changes, as well as air leaks, considerably influence the results. An improved configuration is introduced here by using a mixed water and air controller: the air volume is limited to that present in connection tubes only. With this modification, the volume change of the sample can be satisfactorily measured. However, undetectable air leaks are still possible. The precision of such an improved system is estimated at $\pm 0.22 \mathrm{~cm}^{3}$ representing $0.11 \%$ of a conventional sample volume of $200 \mathrm{~cm}^{3}$.

For the results presented in the following, all triaxial cells were also calibrated to deduce the sample volume change from the cell volume change (following Head, 1986), to allow a rough double check. For some tests, only the water volume changes $\Delta V_{\mathrm{w}}$ and the initial and final degrees of saturation ( $S_{\mathrm{r}_{-} \text {init }}$ and $S_{\mathrm{r}_{-} \text {fin }}$, respectively) were determined. The value of $S_{\mathrm{r}_{-} \text {init }}$ was estimated from the hydric path results using the $w-S_{\mathrm{r}}$ curve and $S_{\mathrm{r}_{-} \text {fin }}$ was measured at the end of the test. The volumetric changes could then be written as $\Delta V=\Delta V_{\mathrm{w}} / S_{\mathrm{r}}$.

\section{Shear Rate}

The shear rate for the drained unsaturated tests (path C-E) was determined in accordance with the classical Gibson and Henkel method (1954). This approach indicates that the complete equalisation of pore water pressure throughout the sample is possible if the time required to fail the sample is set to:

$$
t_{\mathrm{f}}=H^{2} /\left(\eta c_{\mathrm{v}}\left(1-U_{\mathrm{f}}\right)\right)
$$

where

$t_{\mathrm{f}}$ : time required for the sample to fail,

$H$ : half height of the sample (50-55 mm),

$\eta$ : numerical factor depending upon the extent and location of the drainage boundary. For our tests since the water drainage was only performed at the bottom of the sample via the high air value ceramic, $\eta=0.75$,

$U_{\mathrm{f}}$ : average degree of dissipation of the induced pore 
water pressure at failure. Generally 0.95 is assumed to be sufficient to find the soil intrinsic characteristic under drained conditions,

$c_{\mathrm{v}}$ : consolidation coefficient, calculated using Head's relationship (1986):

$$
c_{\mathrm{v}}=T_{90}(2 H)^{2} / t_{90}
$$

$t_{90}$ corresponds to the time at which the soil reaches $90 \%$ of its consolidation for a given load. This was determined from the isotropic consolidation path (C-D) at different values of suction. By proceeding in this fashion, the evolution of the soil permeability with suction, the permeability of the high air entry disc and the drainage boundary were already taken into account.

For example, for a consolidation stress of $400 \mathrm{kPa}$, with a high air entry disc of $500 \mathrm{kPa}$ and a suction of $100 \mathrm{kPa}$ yields: $t_{90}=72000 \mathrm{~s}, T_{90}=0.848$ and $2 H=110$ $\mathrm{mm} \Rightarrow c_{\mathrm{v}}=0.1425 \mathrm{~mm}^{2} / \mathrm{s}$. According to Eq. (1), $t_{\mathrm{f}}=(110 /$ $2)^{2} / 0.75 \cdot 0.1425 \cdot(1-0.95)=566081 s \approx 157 h$. Assuming that failure occurs for an axial strain of almost $10 \%$, a shear rate of $1.2 \mu \mathrm{m} / \mathrm{min}$ has to be set. In the tests, the rate varied between 1.2 and $1.8 \mu \mathrm{m} / \mathrm{min}$ depending on the permeability of the high air entry value ceramic and on the applied stress and suction level. These values are in agreement with those used by Ho and Fredlund (1982) and later by Delage et al. (1987).

\section{RESULTS AND INTERPRETATION}

\section{Drying-Wetting Behaviour (Paths A-H-H')}

Figure 2 shows the characterisation of silt in relation to paths $\mathrm{A}-\mathrm{H}-\mathrm{H}^{\prime}$, performed under zero net pressure $p^{*}$. The simultaneous measurement of water contents and volume changes and their representation, as suggested by Biarez et al. (1988), gives the complete state of the soil. This representation includes: (a) the shrinkage curve showing the void ratio $e$ as a function of water content $w$, (b) the consolidation plane showing $e$ as a function of suction (logarithmic scale), (c) the degree of saturation $S_{\mathrm{r}}$ as a function of $w$, (d) $S_{\mathrm{r}}$ as a function of suction (logarithmic scale), and (e) the usual retention curve showing $w$ as a function of the suction (logarithmic scale).

Three different symbols are represented: (i) the circles correspond to drying of the samples, with a slurry at an initial water content of $1.5 w_{\mathrm{L}}$, (ii) the triangles represent samples first dried to a given suction of $300 \mathrm{kPa}$ and then wetted by decreasing the suction, (iii) the crosses correspond to samples first dried in the oven at $105^{\circ} \mathrm{C}$ and then wetted by decreasing the suction.

Figure 2 demonstrates that this soil remains almost saturated on a drying path below the air-entry suction, $s_{\mathrm{e}}$, which is approximately $50 \mathrm{kPa}$ (see Fig. 2(c) and 2(d)). Further increasing the suction led to a significant reduction in $S_{\mathrm{r}}$, though such reduction tapers off above a suction value of $400 \mathrm{kPa}$ (Fig. 2(d)). Note that the relationship between water content and degree of saturation is the same in all three cases (Fig. 2(c)).

The experimental results also reveal the hysteretic nature of the behaviour that occurs, when the samples are wetted after having been dried at a suction of $300 \mathrm{kPa}$ (see Figs. 2(d) and 2(e)). Note that, no hysteresis is present for the oven-dried samples. This result confirms that there is a behavioural difference between oven-dried samples and samples subjected to high suctions (where considerable hysteresis would be expected).

Figure 2(b) shows the suction consolidation plane. The scatter of the data is quite important, as an error of $2 \%$ on the volume measurement implies an error of about $5 \%$ on the void ratio value. Starting from initial void ratio of $0.9-1.0$ for $s=0$ (not shown in this logarithmic plane), the void ratio reduces to about 0.7 for suction values of $100 \mathrm{kPa}$. Due to the data scatter, the compressibility index cannot be determined. Note that fitting a straight line through the triangle marks (wetting path) yields a slope of around 0.017 . This value can be compared with the unloading saturated compressibility from isotropic compression ( $\kappa \approx 0.004$ to 0.011 ).

The shrinkage curve (Fig. 2(a)) confirms the observations of other authors (Biarez et al., 1988; Fleureau and Indatro, 1993). When the water content decreases, the void ratio first follows a line close to the saturation curve (i.e. $e=\left(\gamma_{\mathrm{s}} / \gamma_{\mathrm{w}}\right) w$ ) and then decreases slightly.

\section{Isotropic Compression Tests on Unsaturated Samples (Path C-D)}

Isotropic compression tests were conducted by increasing the pressure in steps at pre-selected values of suction between 0 and $280 \mathrm{kPa}$ (Fig. 3(a)). Only water volumetric strains $\varepsilon_{\mathrm{VW}}$ (defined as the variation of the water volume $\Delta V_{\mathrm{w}}$ over the initial total volume $V_{\mathrm{o}}, \varepsilon_{\mathrm{vW}}=\Delta V_{\mathrm{w}} / V_{0}$ ) were recorded in this first series. All samples were preconsolidated under saturated conditions to an effective mean pressure of $300 \mathrm{kPa}$ and then dried to a given level of suction $\left(0,100,200\right.$ and $280 \mathrm{kPa}$ ) while keeping $p^{\prime}$ (saturated effective pressure), at $300 \mathrm{kPa}$, before starting the isotropic compression (path ABCD, Fig. 1). The estimated yield points (in a $p^{\prime}$ logarithmic representation) are identified by a change in slope. For the case of $s=100$ $\mathrm{kPa}$, no clear yield point is detectable. Plotting the yield pressure in terms of both $p^{*}$ (net pressure) and $p^{\prime}$ versus suction allows the examination of the variation of yield locus (Fig. 3(b)). Up to the suction corresponding to the air-entry value, one would expect the yield curve to be vertical in the $s-p^{\prime}$ plot (because behaviour under saturated conditions is governed solely by $p-u_{\mathrm{w}}$ ) and inclined at $45^{\circ}$ from the vertical in the $s-p^{*}$ plot $\left(p^{*}=p^{\prime}-s\right)$. There is a simple mapping between the two curves separated by the magnitude of suction applied.

Isotropic consolidation tests give information on the variation of the compressibility with suction. $\lambda^{\prime}$ is defined as the elasto-plastic slope in the $\ln \left(p^{\prime}\right)$ versus $e$ plane and $\lambda^{*}$ as the corresponding compressibility in a $\ln \left(p^{*}\right)$ versus $e$ plane. The values are summarised in Fig. 4 for the Sion silt and also for other soils from the literature: Jossigny silt (Vicol, 1990), Trois-Rivières silt (Maâtouk et al., 1995), kaolin (Wheeler and Sivakumar, 1995 and Sivakumar, 1993), Steerbeek silt (Leclercq and 

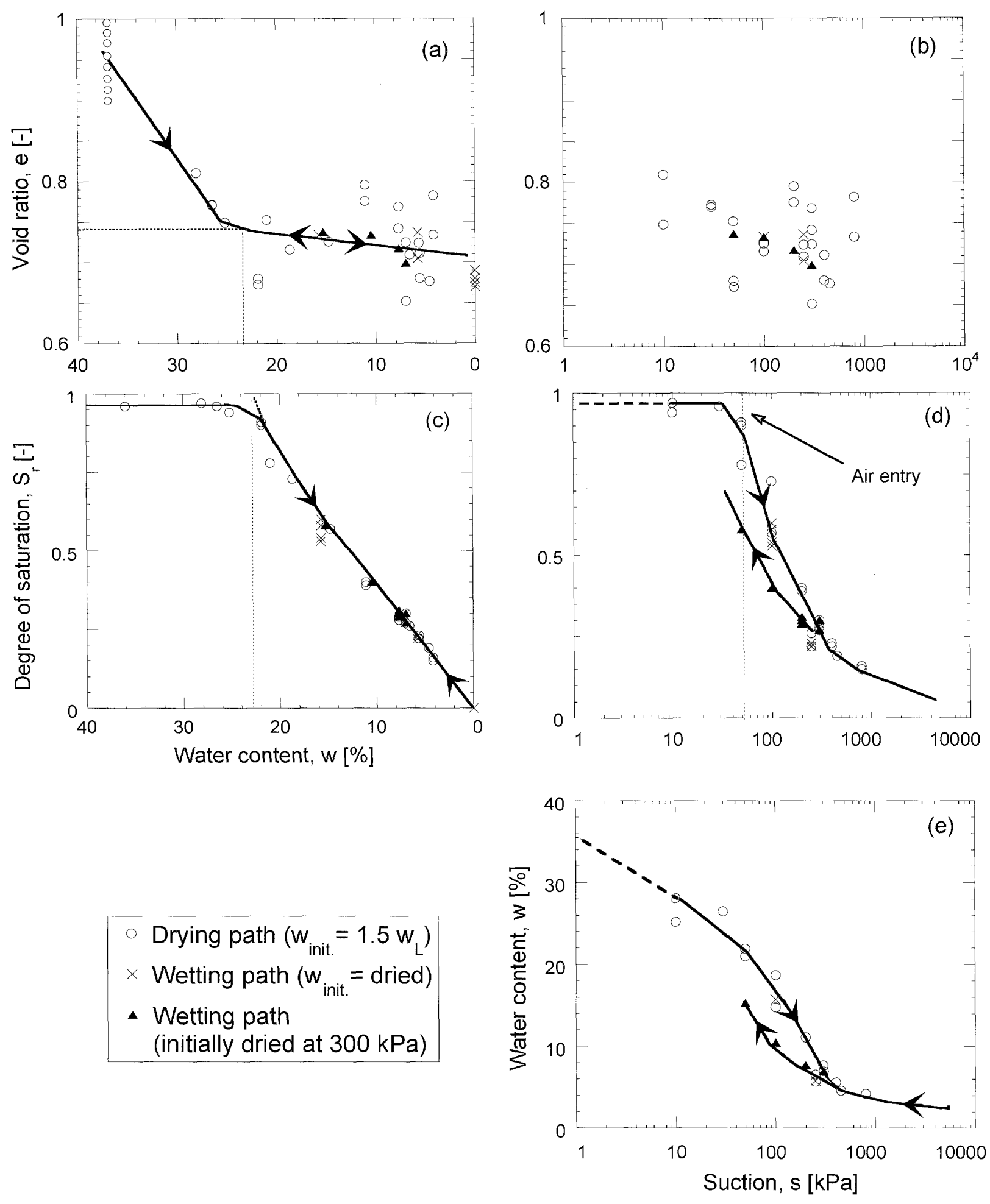

Fig. 2. Behaviour of the Sion silt under drying and wetting paths (pressure plate)

Verbrugge, 1985), kaolin (Matyas and Radhakrishna, 1968). For several of the soils shown in Fig. 4(b) an initial increase of $\lambda^{*}$ at low suction value is noticed, followed by a reduction.

\section{Drained Shear Tests (Paths C-E)}

Figure 5 shows the stress and strain data for triaxial drained shear tests at a constant "saturated effective" confining pressure of $\sigma_{3}^{\prime}=600 \mathrm{kPa}$ and at different suction levels $(s=0,50,100,200$ and $280 \mathrm{kPa})$. The initial modulus and the maximum deviatoric stress tend to gradually increase with increasing suction. In saturated soils, suction and $p^{\prime}$ (under isotropic loading conditions) have similar effects on the volume change and shear strength (Laloui et al., 2005). Each sample showed a peak deviatoric stress which was then followed by a gradual 


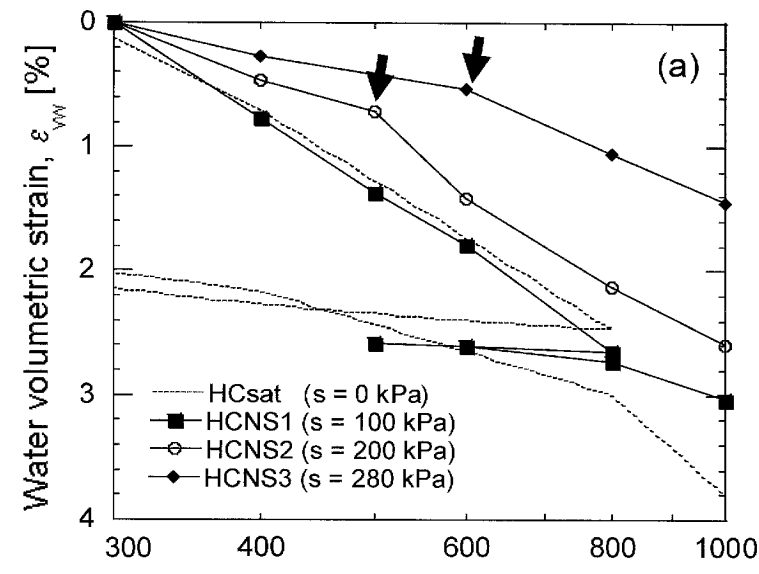

Saturated effective mean pressure, p' [kPa]

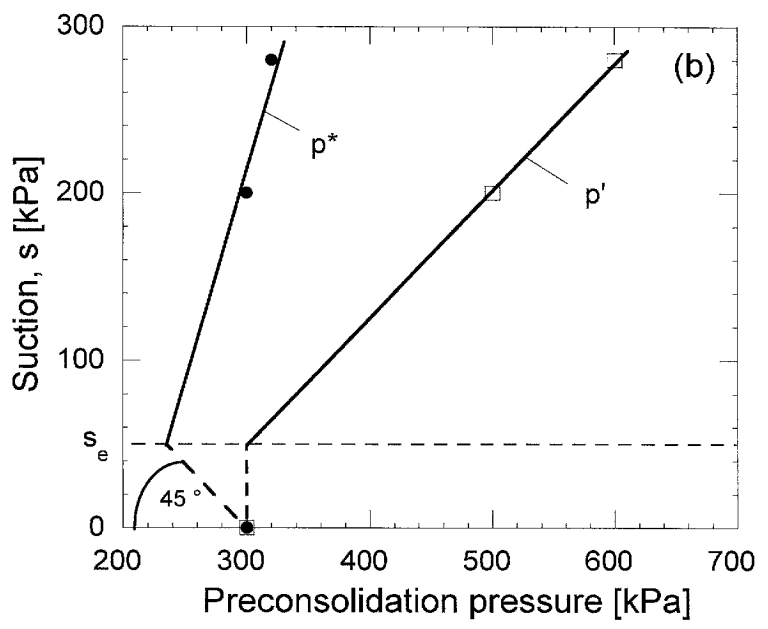

Fig. 3. Unsaturated isotropic tests: (a) experimental results and yielding points and (b) evolution of the preconsolidation pressure with suction

reduction towards critical state. Visual observation of the samples has shown that the decreasing stress after the peak coincides with the development of shear bands. The test at $s=280 \mathrm{kPa}$ (corresponding to $S_{\mathrm{r}} \approx 30 \%$ ) presented a different behaviour, in which shear bands started to develop early in the test and the strength could not be mobilized.

Figure 5(b) illustrates the volumetric strain, in which the samples showed compression which was followed by dilation as the shearing progressed. The amount of dilation increased with increasing suction.

Drained shear tests at the constant net confining pressure of $\sigma_{3}^{*}=400 \mathrm{kPa}$ and at different suction levels $(s=0,50,100$ and $200 \mathrm{kPa})$ are plotted in Fig. 6. As in the previous tests, the initial modulus and the maximum deviatoric stress gradually increase with suction. This behaviour is similar to that observed in saturated condition for tests performed under increasing confining pressure. However, in this case even for a large value of axial strain, $q$ never reaches a unique residual value.

\section{Constant Water Content Shear Tests (Paths C-F)}

In this series of tests, samples were consolidated to three different values of saturated effective confinement


Fig. 4. Compressibility as a function of suction in (a) a saturated effective stress approach and (b) a net mean stress approach for different soils

pressure $\sigma_{3}: 200,300$ and $1000 \mathrm{kPa}$. The relevant stressstrain relationships are shown in Fig. 7.

Shear bands appear before the peak in deviatoric stress when the ratio between the initial suction $s$ and $\left(\sigma_{3}^{\prime}\right)_{\text {init }}$ is large (typically, for Sion silt, when the ratio $s /\left(\sigma_{3}^{\prime}\right)_{\text {init }}$ is over 0.45 ). For ratios down to 0.3 , localisation can still appear, but this occurs after the peak. For ratios smaller than 0.3 (Fig. 7(c)), no significant suction-induced effects can be observed implying that the drying effects are negligible in comparison to the compression effects.

The relationship between $\varepsilon_{1}$ and $u_{\mathrm{w}}$ (and $s$ ), represented in Fig. 7, mainly shows that the built up pore-water pressure is smaller for unsaturated than for saturated samples, as the fluid in the unsaturated case is a mixture of air and water and thus is more compressible.

\section{Elastic Behaviour}

In order to describe the elastic behaviour of Sion silt, an unloading path was usually performed at about $2 \%$ of axial strain during the shearing tests. Two different "elastic" moduli are defined: (i) the secant modulus $E_{\mathrm{s}}$ defined as the slope in the $\varepsilon_{1}-q$ graph at a given axial strain $\varepsilon_{1}$ of $0.5 \%$ and (ii) the unloading modulus $E$ defined as the average slope in the $\varepsilon_{1}-q$ plane during unloading. 

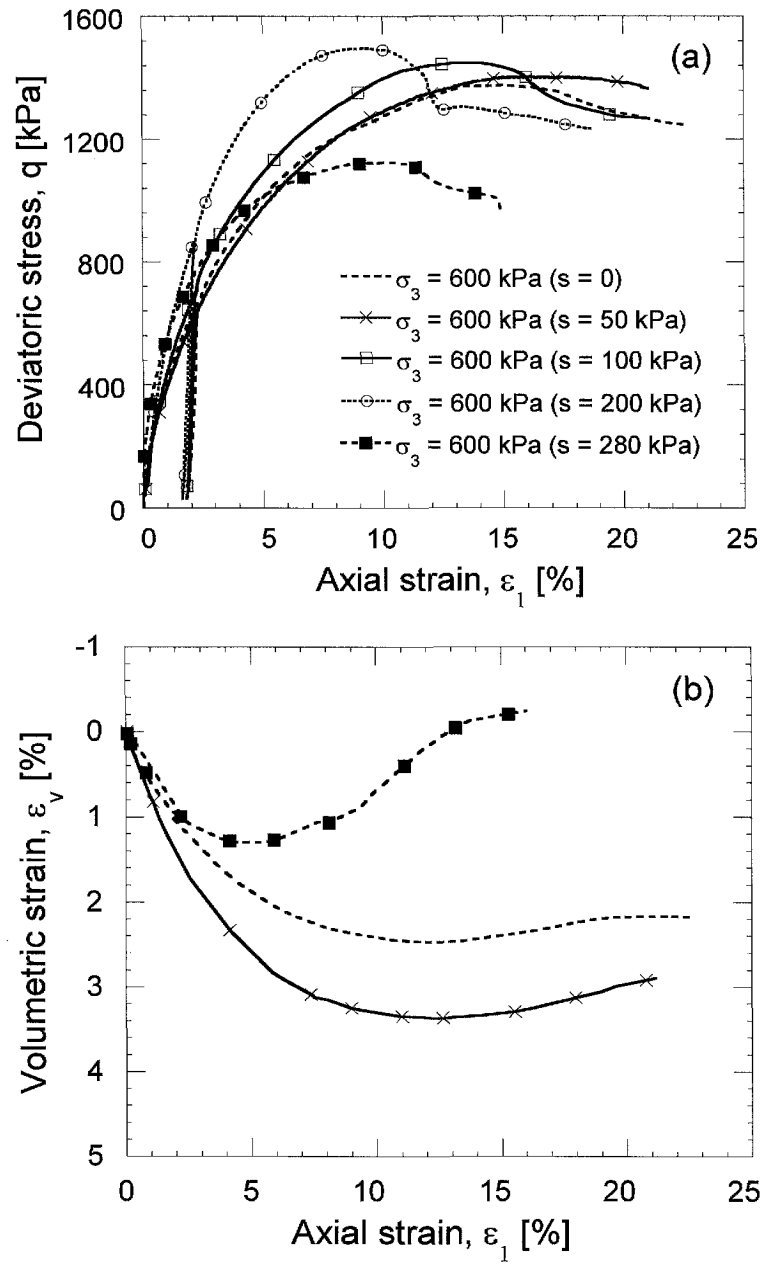

Fig. 5. Drained shearing tests at an effective confining pressure $\sigma_{3}^{\prime}$ of $600 \mathrm{kPa}$ and at different suction levels $(s=0,50,100,200$ and 280 $\mathrm{kPa}$ ): Axial strain $\varepsilon_{1}$ versus (a) deviatoric stress $q$ and (b) volumetric strain $\varepsilon_{v}$

Figure 8 shows these moduli as a function of suction at different levels of "saturated effective", $p^{\prime}$, and net mean stress, $p^{*}$. As would be expected, suction increases the stiffening of the soil at a given confining stress $\sigma_{3}^{\prime}$ or $\sigma_{3}^{*}$. Similar observations were made by Fleureau (1992), Cui (1993) and Lagny (1996).

\section{Peak Strength}

Peak strength $q_{\text {peak }}$ obtained from constant water content tests are plotted as function of suction in Fig. 9. It can be seen that $q_{\text {peak }}$ increases with suction for low values of effective confining pressure $\left(\sigma_{3 \text { init }}^{\prime}=200 \mathrm{kPa}\right)$ but slightly decreases for high values of effective confining pressure $\left(\sigma_{3 \text { init }}^{\prime}=1000 \mathrm{kPa}\right) . \quad \sigma_{3 \text { init }}^{\prime}=300 \mathrm{kPa}$ represents an intermediate state. In Fig. 9(b), the results are scaled by dividing $q_{\text {peak }}$ by the effective confining pressure. Note that a maximum value of $q_{\text {peak }} / \sigma_{3 \text { init }}^{\prime}=3.1$ is found close to a suction value equivalent to the air-entry value $\left(s_{\mathrm{e}}=50\right.$ $\mathrm{kPa})$.

The points representing the peak deviatoric stress versus the corresponding net mean pressure $p^{*}$ are plotted in Fig. 10 for tests on unsaturated samples. The saturated
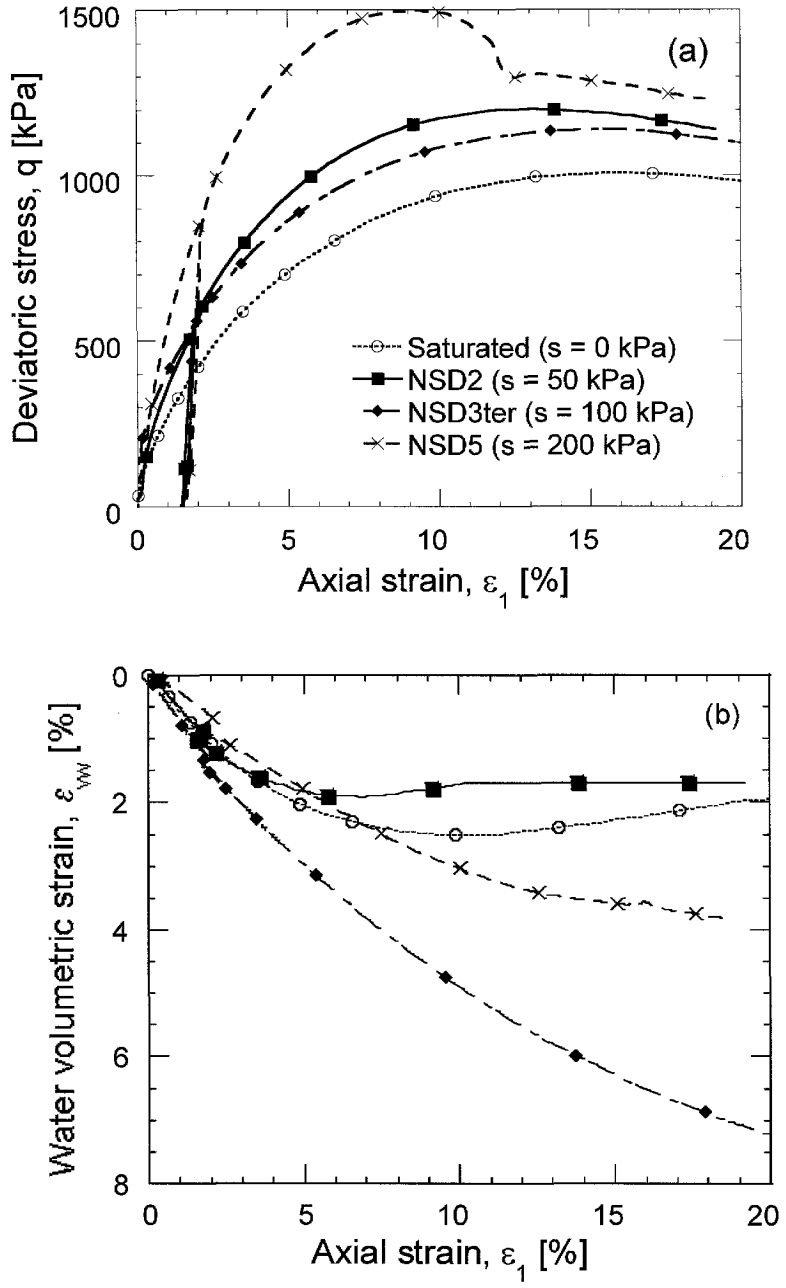

Fig. 6. Drained shearing tests at a net confining pressure $\sigma_{3}^{*}$ of 400 $\mathrm{kPa}$ and at different suction levels $(s=0,50,100$ and $200 \mathrm{kPa})$ : Axial strain $\varepsilon_{1}$ versus (a) deviatoric stress $q$ and (b) water volumetric strain $\varepsilon_{\mathrm{vw}}$

case is represented by the critical state line at saturation (CSL), as the peak strength and the strength at critical state are close for normally consolidated tests on saturated samples. Lines are plotted through the peak strength points determined at the same suction level. The present data on the Sion silt show that intercept $a$ ( $a$ measure of cohesion) increases with suction, while the slope $\left(\eta_{\text {peak }}\right)$ remains almost constant.

Figure 11(a) shows, as a comparison, the friction angle $\phi_{\text {peak }}$ as a function of suction for different soils. This figure is based on a summary proposed by Delage and Graham (1995), the data on Al-Agoza clay (Mashhour et al., 1995) and our own results. No clear trend can be observed for the variation of the friction angle $\phi_{\text {peak }}$. For the silts, it appears that $\phi_{\text {peak }}$ decreases with suction, particularly for Trois-Rivières silt, which is a relatively collapsible soil. In comparison, Sion silt is not collapsible and $\phi_{\text {peak }}$ is almost constant. The cohesion as a function of suction (Fig. 11(b)) is similar for all the soils (except Trois-Rivières silt), leading to some simplifications in the modelling of shear strength of unsaturated soils.

When the peak shear strength points are plotted, in a 


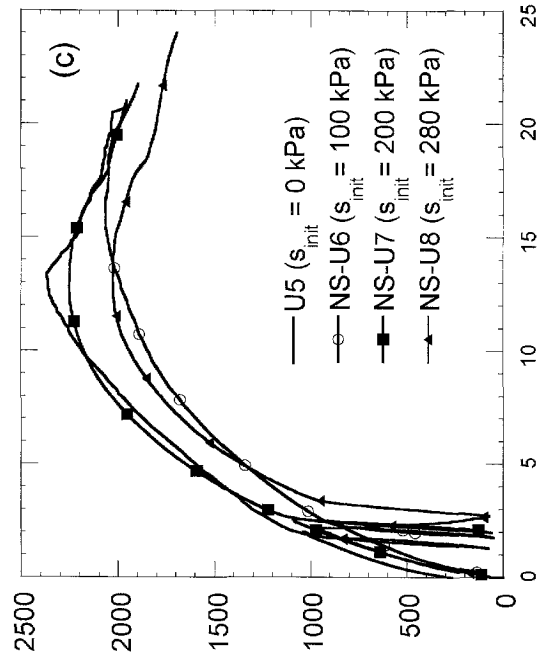

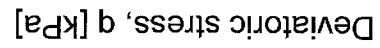

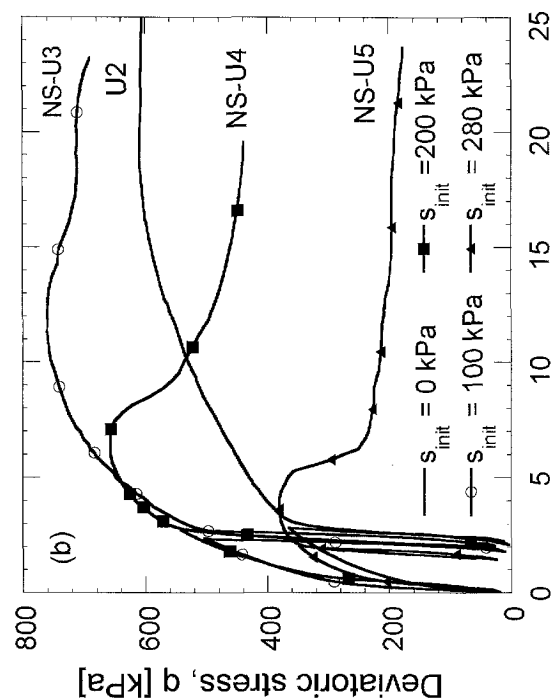

[edy] b 'ssәns o!̣ole!nı



Fig. 7. Constant water content shearing tests: (a) $\left(\sigma_{3}^{\prime}\right)_{\text {init }}=200 \mathrm{kPa}$, (b) $\left(\sigma_{3}^{\prime}\right)_{\text {init }}=300 \mathrm{kPa}$ and $\left(\right.$ c) $\left(\sigma_{3}^{\prime}\right)_{\text {init }}=1000 \mathrm{kPa}$

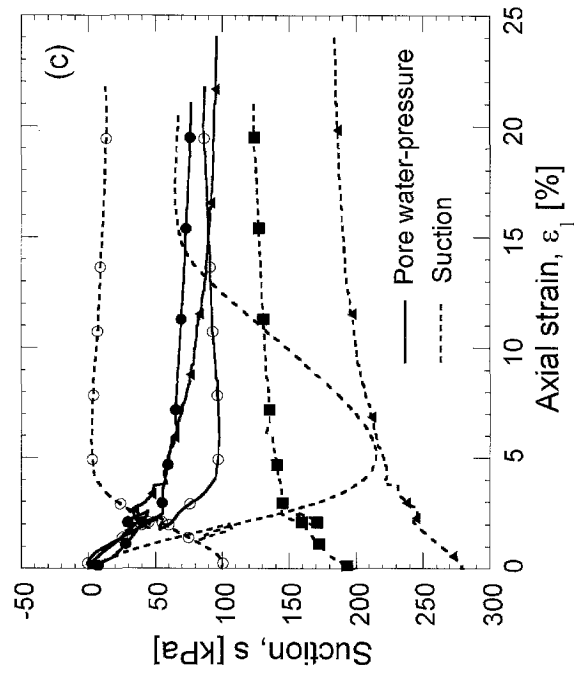

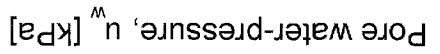
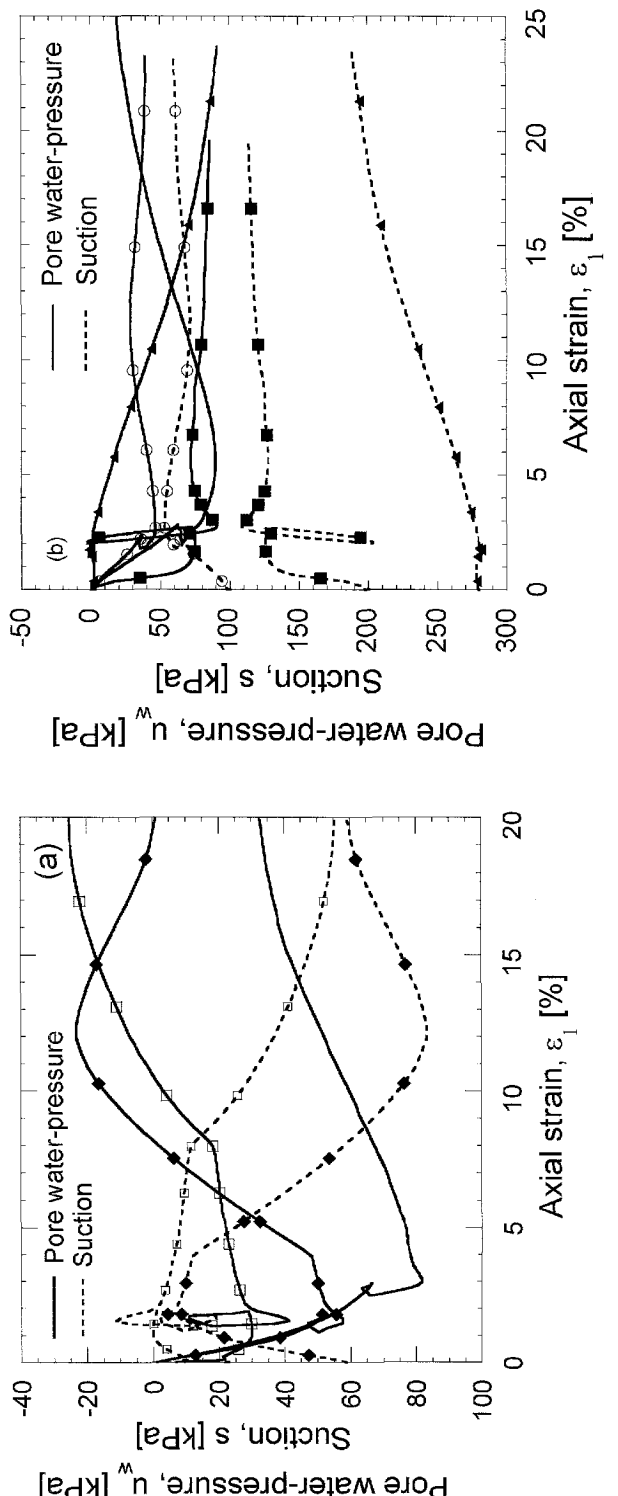

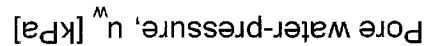






Fig. 8. Elastic moduli as a function of suction for Sion silt
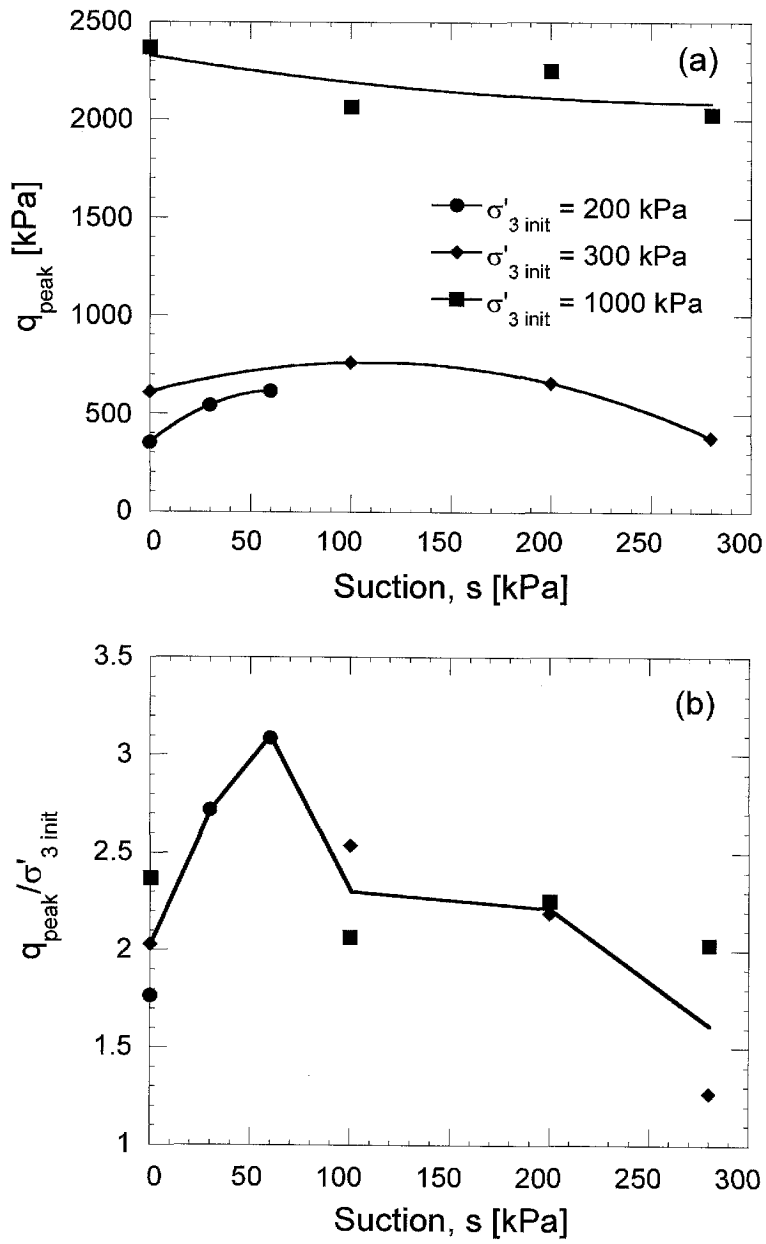

Fig. 9. Peak deviatoric stress as a function of suction (constant water content tests)

$p^{\prime}-q$ plane (Fig. 12), the slope connecting them, $\eta_{\text {peak }}$, can once more be assumed to be constant. The cohesion also increases (all the points with $s>0$ are situated on or above the CSL line at $s=0$ ). Quantitatively the effect is less pronounced than in the $p^{*}-q$ plane.

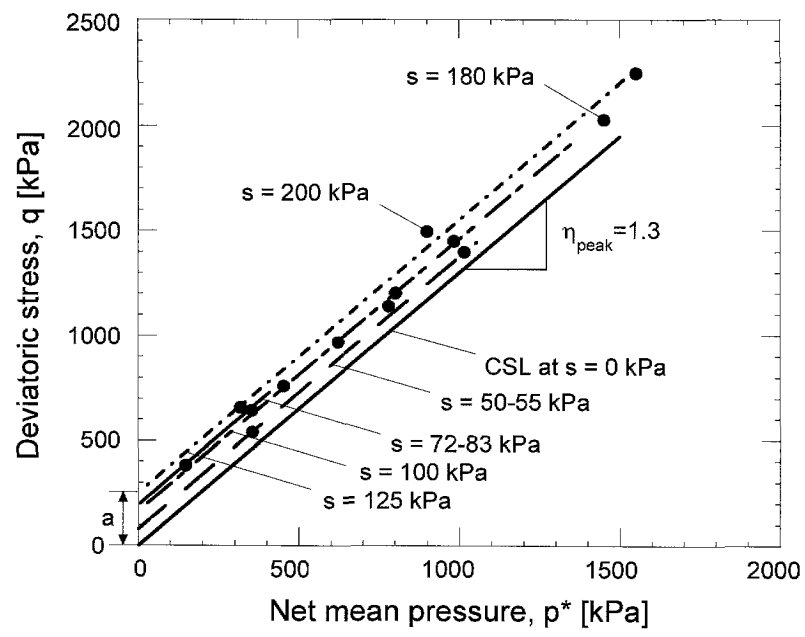

Fig. 10. Peak strength for different suctions in the $p^{*}-q$ plane (individual values of suction are given in Fig. 12)
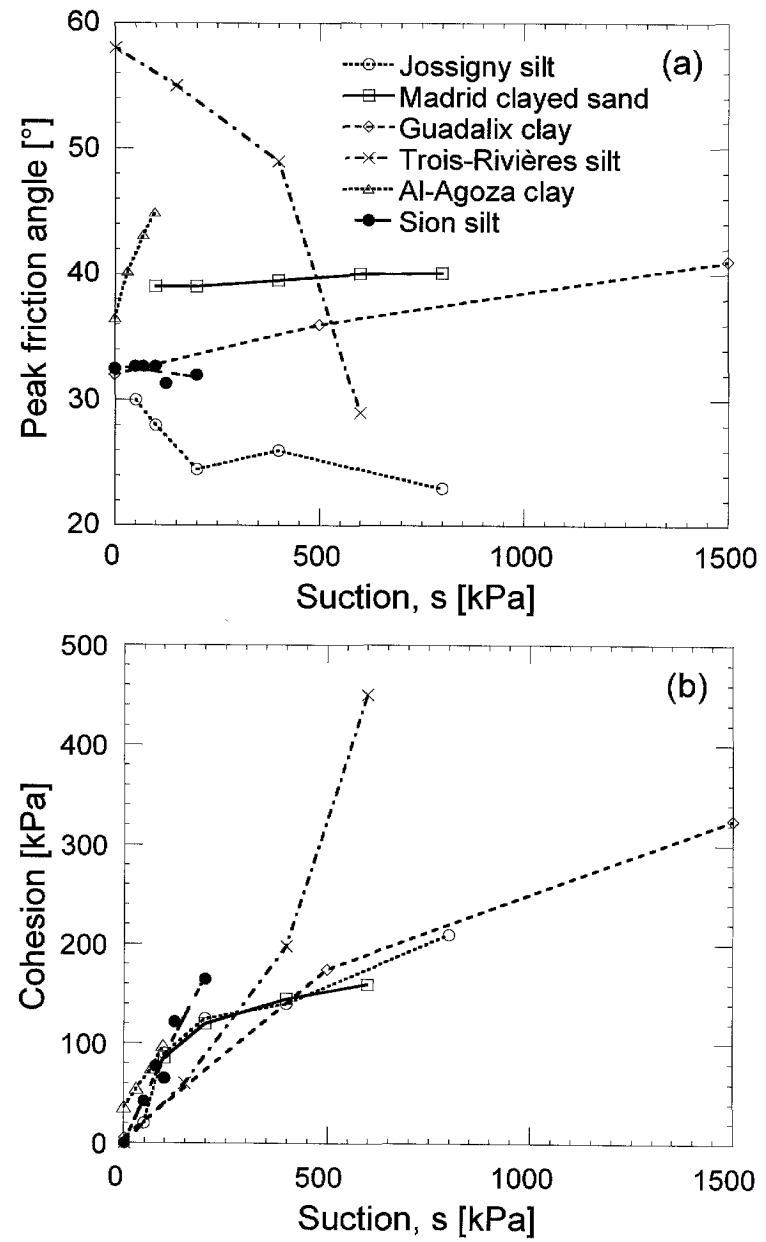

Fig. 11. Friction angle (a) and cohesion (b) at peak strength versus suction (net mean stress interpretation)

\section{Critical State}

While significant research efforts have addressed the relationship between shear strength and suction, only a few have examined the effect of suction on critical state (e.g. Toll 1990; Wheeler and Sivakumar, 1995; Maâtouk et al., 1995). The tests on saturated samples are plotted in 
Fig. 13 for the Sion silt: the Critical State Line (CSL) has a slope of $M=1.3$ with a correlation coefficient $r$ of 0.99 .

All the points corresponding to unsaturated samples (solid dots) are close to the CSL line. The scattering of the experimental points is similar to that observed in saturated conditions. This would mean that the critical state is

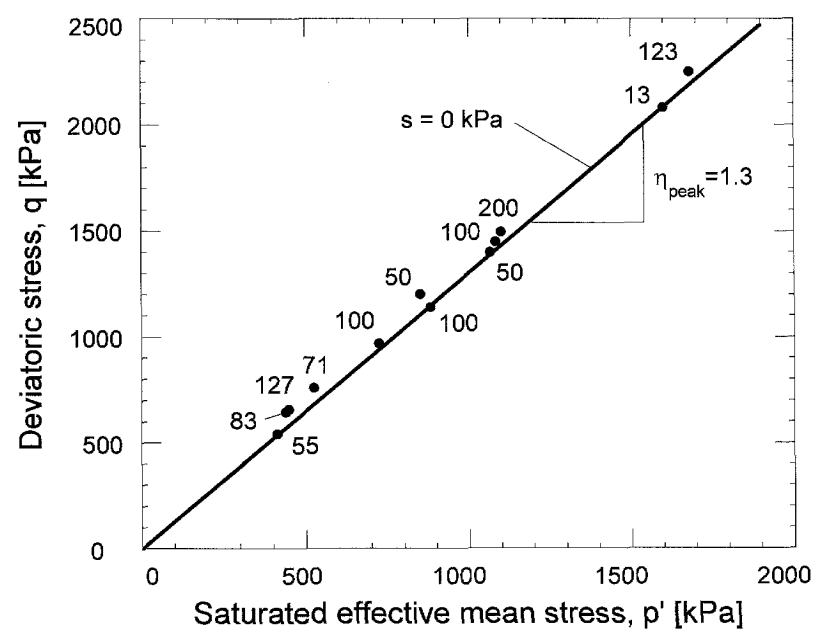

Fig. 12. Peak strength for different suctions in the $p^{\prime}-q$ plane

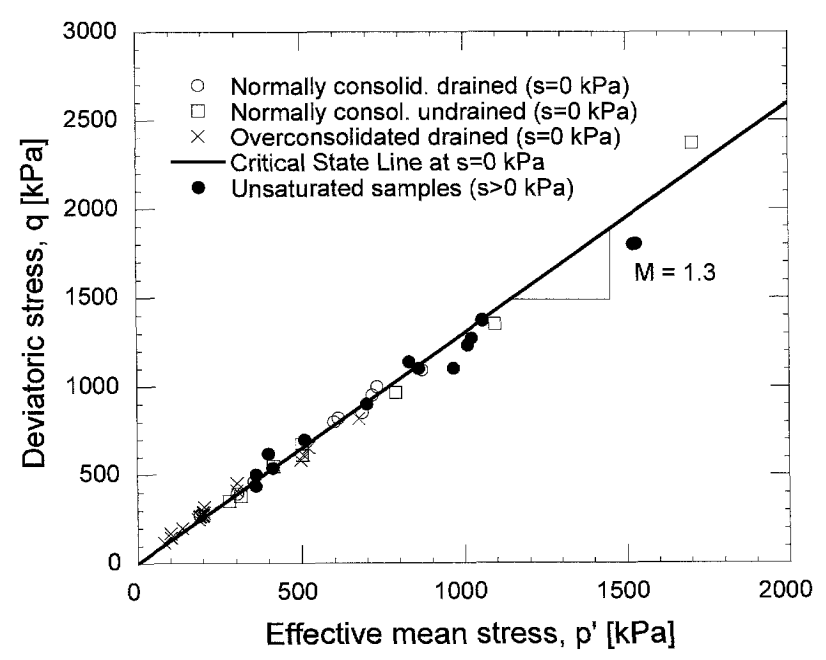

Fig. 13. Critical state line for saturated and unsaturated states

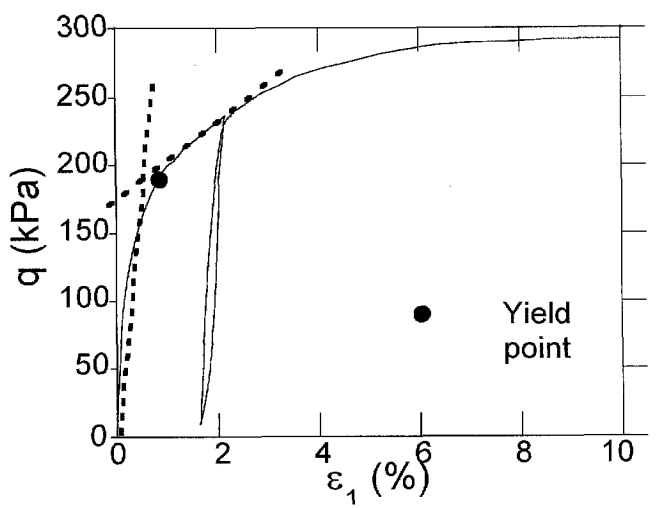

uniquely defined in a $p^{\prime}$ interpretation for the considered levels of suction. Taibi (1994) has obtained similar results for unsaturated soils.

Figure 14 shows the critical state points in a $p^{*}$ interpretation, where a unique line can no longer describe the CSL. The results seem to be similar to those described by Maâtouk et al. (1995), with a decreasing slope $M$ and an increasing cohesion with suction, respectively.

\section{Yielding}

The knowledge of the shape of the yield locus and its variation with suction is an important aspect of behaviour. Few experimental results are available in the literature for the determination of yield locus in the case of unsaturated soils (Zakaria et al., 1995; Cui and Delage, 1996; Geiser et al., 1998). The procedure used to determine the yield surface is as follows. The samples are first loaded isotropically with a consolidation pressure $p_{c}^{\prime}=400$, respectively $600 \mathrm{kPa}$. They are then unloaded to different values of confining pressures prior to shearing. The defined yield limit then corresponds to the highest value of the mean effective stress (400, respectively 600 $\mathrm{kPa}$ ) and a specific void ratio. The unloading steps moved the stress state inside this yield surface. Since the stress

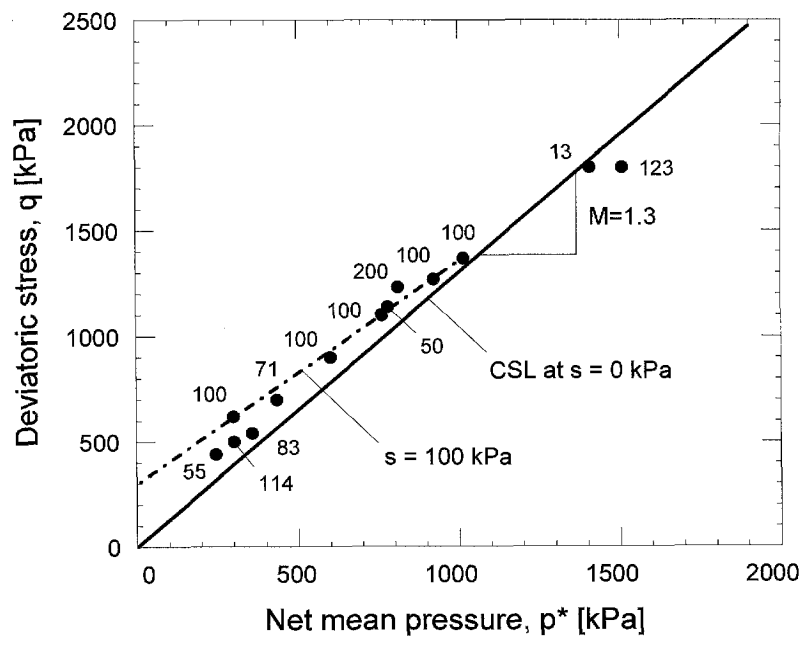

Fig. 14. Critical state line for different suctions in the $p^{*}-q$ plane

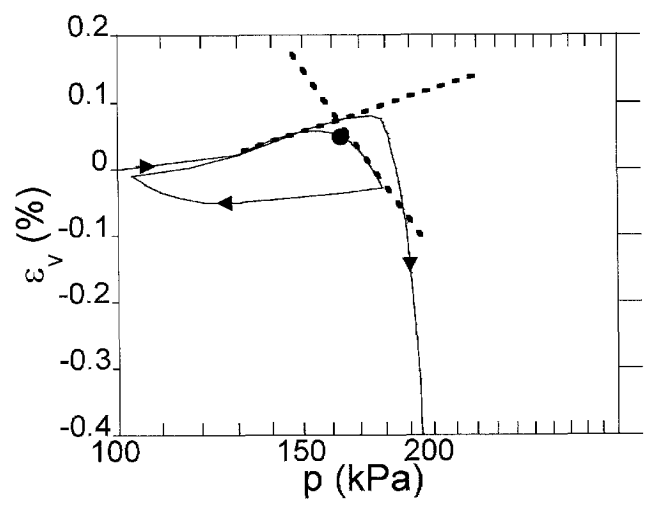

Fig. 15. Identification of the yield point in the case of a triaxial test 


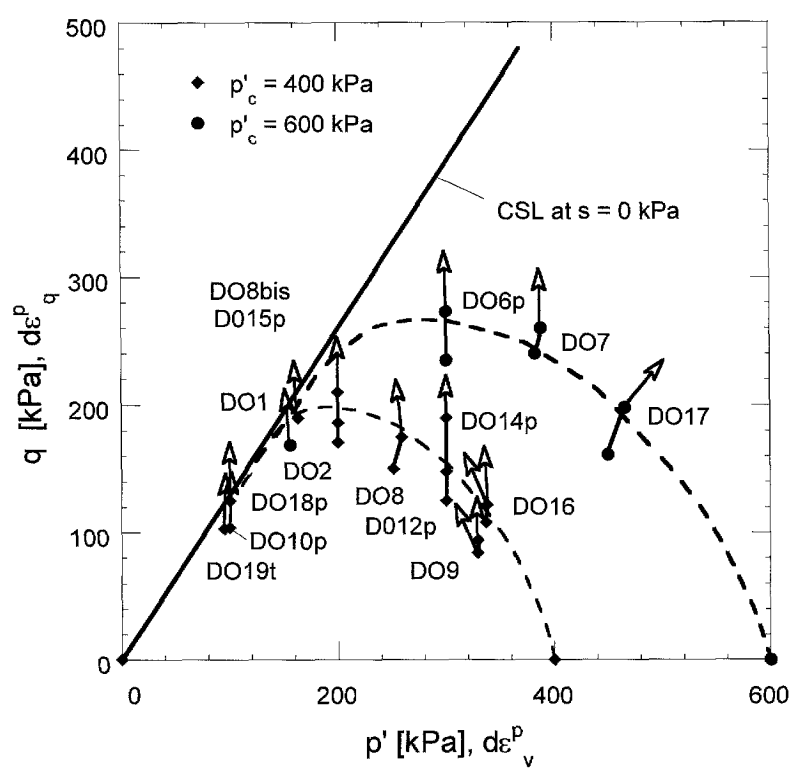

Fig. 16. Stress paths, yield points and plastic strain vector increments under saturated conditions

point was within the yield surface, initial strains due to a shear stress would be mainly elastic, until the stress point reached the yield surface, and after that it became plastic. The combination of pre-yield and post-yield linearity permits bilinear extrapolation techniques for identifying the yield point (Graham et al., 1982). Yield points are determined from a stress-strain criterion by using various procedures, all consisting of identifying a change of slope in the stress-strain planes (Fig. 15).

Figure 16 shows the yield points in saturated conditions represented in the $p^{\prime}-q$ plane, together with the plastic strain increments at the onset of yielding. In this figure, the yield locus corresponding to two consolidation pressures are drawn by interpolation. The behaviour would clearly be represented by a non-associated flow rule.

Figure 17 shows the effect of suction on the yield surface at a saturated preconsolidation pressure $p_{\mathfrak{c}}^{\prime}$ of 600 $\mathrm{kPa}$. Although a complete determination of the yield locus is not possible based on so few points (including data points for isotropic loading $q=0$ ), the general trend of suction hardening is clearly visible (see continuous lines). The effect of suction can be seen as a result of a suction-induced preconsolidation. Similar results were obtained for compacted unsaturated soils (Zakaria et al., 1995; Cui and Delage, 1996). Similar results are observed in a $p^{*}$ representation (Geiser, 1999).

\section{CONCLUSIONS}

A remoulded silt has been subjected to various loading paths, and the interpretation of the resulting data contribute to our understanding of the behaviour of unsaturated soils.

The drying-wetting tests confirmed the hysteretic nature of the behaviour. Under more general loading

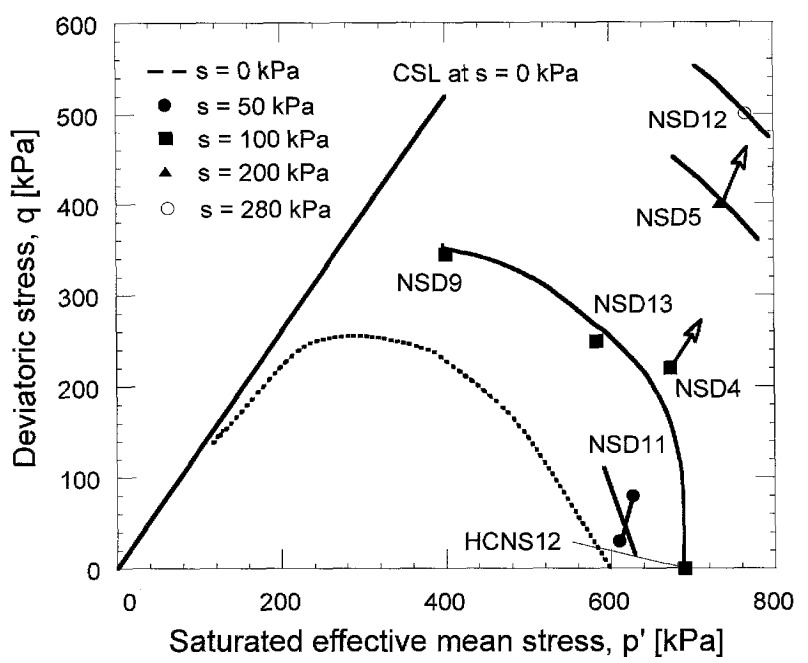

Fig. 17. Yield points under unsaturated conditions in an saturated effective stress representation for a saturated preconsolidation pressure of $600 \mathrm{kPa}$

paths, it was found that the behaviour is different in terms of volume variation when the suction increases above the air entry value. Isotropic compression tests at constant suction revealed that the preconsolidation pressure increases with the suction in the "effective stress" approach. This increase is not as pronounced rather limited in the net stress approach. From the triaxial shear test, an increase of stiffness and peak strength with suction at constant mean effective or net pressures is only shown for low confining stress. Suction appears to have an effect similar to that of mechanical overconsolidation when representing the results in the effective stress plane. Softening appears post-peak for the cases of high suction or low net mean pressure. In the $p^{\prime}-q$ plane, the critical state line is shown to be independent of suction (in the studied range of stress and suction); this is not the case in the $p^{*}-q$ plane. Finally, it is shown that the yield locus increased with suction.

\section{ACKNOWLEDGEMENTS}

This work was funded by the Swiss NSF, grant 21-42360.94. The authors gratefully thank Mr. G. Gruaz for his help in performing the laboratory testing.

\section{REFERENCES}

1) Alonso, E. E., Gens, A. and Josa, A. (1990): A constitutive model for partially saturated soils, Géotechnique, 40(3), 405-430.

2) Biarez, J., Fleureau, J. M., Zerhouni, M. I. and Soepandji, B. S. (1988): Variations de volumes des sols argileux lors de cycles de drainage-humidification, Revue Française de Géotechnique, 41, $63-71$.

3) Blight, G. E. (1966): Strength characteristics of dessicated clays, ASCE J. Soil Mech. Found. Engrg. Div., 92, 19-37.

4) Croney, D. and Coleman, J. D. (1954): Soil structure in relation to soil suction, J. Soil Science, 5, 75-84.

5) Cui, Y. J. (1993): Etude du comportement d'un limon compacté non saturé et de sa modélisation dans un cadre élasto-plastique, PhD Thesis, Ecole nationale des Ponts et Chaussées, Paris. 
6) Cui, Y. J. and Delage, P. (1996): Yielding and plastic behaviour of an unsaturated compacted silt, Géotechnique, 46 (2), 291-311.

7) Delage, P. and Graham, J. (1995): Mechanical behaviour of unsaturated soils: Understanding the behaviour of unsaturated soils requires conceptual models, Proc. Int. Conf. Unsaturated Soils, Paris, 1223-1256.

8) Delage, P., Suraj de Silva, G. P. R. and de Laure, E. (1987): Un nouvel appareil triaxial pour les sols non saturés, Proc. 9th Eur. Conf. SMFE, Dublin, 1, 26-28.

9) Escario, V. and Saez, J. (1986): The shear strength of partly saturated soils, Géotechnique, 36 (3), 453-456.

10) Fleureau, J. M. (1992): Contribution à l'étude et à la modélisation des materiaux polyphasiques, Habilitation Thesis, Ecole Centrale Paris.

11) Fleureau, J. M. and Indarto (1993): Comportement du limon de Jossigny remanié soumis à une pression interstitielle négative, Revue Française de Géotechnique, 62, 59-66.

12) Fleureau, J. M., Kheirbek-Saoud, S., Soemitro, R. and Taibi, S. (1993): Behavior of clayed soils on drying-wetting paths, Can. Geotech. J., 30, 287-296.

13) Fleureau, J. M., Kheirbek-Saoud and Taibi, S. (1995): Experimental aspects and modelling of the behaviour of soils with a negative pressure, Proc. Int. Conf. Unsaturated Soils, Paris, 57-62.

14) Fredlund, D. G. and Morgenstern, N. R. (1977): Stress state variables for unsaturated soils, ASCE-GT5, 447-465.

15) Fredlund, D. G. and Rahardjo, H. (1993): Soil Mechanics for Unsaturated Soils, John Wiley and Sons.

16) Fredlund, D. G., Morgenstern, N. R. and Widger, R. A. (1978): The shear strength of unsaturated soils, Can. Geotech. J., 15, 313-321.

17) Geiser, F. (1999): Comportement mécanique d'un limon non saturé: étude expérimentale et modélisation constitutive, $P h D$ Thesis, Swiss Federal Institute of Technology, Lausanne.

18) Geiser, F., Laloui, L. and Vulliet, L. (1998): Yielding of a remoulded sandy silt in saturated and unsaturated states, Proc. 2nd Int. Conf. Unsaturated Soils, 1, Beijing, 54-59.

19) Geiser, F., Laloui, L. and Vulliet, L. (2000): On the volume measurement in unsaturated triaxial test, Unsaturated Soils for Asia (eds. by Rahardjo, Toll and Leong), Balkema, 669-674.

20) Gibson, R. E. and Henkel, D. J. (1954): Influence of duration of tests at constant rate of strain on measured drained strength, Géotechnique, 4 (1), 6-15.

21) Graham, J., Pinkney, R. B., Lew, K. V. and Trainor, P. G. S (1982): Curve fitting and laboratory data, Can. Geotech. J., 19, 201-205.

22) Head, K. H. (1986): Manual of Soil Laboratory Testing, Pentech Press.

23) Ho, D. Y. F. and Fredlund, D. G. (1982). A multistage triaxial test for unsaturated soils, Geotech. Test. J., 5 (1), 18-25.

24) Karube, D. and Kawai, K. (2001): The role of pore water in the mechanical behavior of unsaturated soils, Geotech. Geolog.
Engrg., 19 (3), 211-241.

25) Kohgo, Y., Nakano, M. and Miyazaki, T. (1993): Theoretical aspects of constitutive modeling for unsaturated soils, Soils and Foundations, 33 (4), 49-63.

26) Lagny, C. (1996): Comportement mécanique des sols fins sous fortes contraintes et fortes pressions négatives, $P h D$ Thesis, Ecole Centrale Paris.

27) Laloui, L. and Nuth, M. (2005): An introduction to the constitutive modelling of unsaturated soils, REGC (Eur. J. Civil Engineering), $9(5-6), 651-670$.

28) Laloui, L., Péron, H., Geiser, F., Rifa'i, A. and Vulliet, L. (2006): Advances in volume measurement in unsaturated triaxial tests, Soils and Foundations, 46 (3), 341-350.

29) Leclercq, J. and Verbrugge, J. C. (1985): Propriétés géomécaniques des sols non saturés. Compte-rendus du Colloque sur le travail du sol, Faculté des Sciences Agronomiques Gembloux.

30) Maâtouk, A., Leroueil, S. and la Rochelle, P. (1995): Yielding and critical state of a collapsible unsaturated silty soil, Géotechnique, 45 (3), 465-477.

31) Mashhour, M. M., Ibrahim, M. I. and El-Eman, M. M. (1995): Variation of unsaturated soil shear strength parameters with suction, Proc. Int. Conf. Unsaturated Soils, Paris, 1487-1493.

32) Matyas, E. L. and Radhakrishna, H. S. (1968): Volume change characteristics of partially saturated soils, Géotechnique, 18 (4), $432-448$.

33) Peron, H., Hueckel, T. and Laloui, L. (2006): An improved volume measurement in determining soil water retention curve, Geotech. Test. J., 20 (1).

34) Sivakumar, V. (1993): A critical state framework for unsaturated soils, $P h D$ Thesis, University of Sheffield.

35) Soil Moisture Equipment Corporation (1985): Commercial publications, P.O. Box 30025, Santa Barbara, CA, USA.

36) Taibi, S. (1994): Comportement mécanique et hydraulique des sols partiellement saturés, PhD Thesis, Ecole Centrale Paris.

37) Toll, D. G. (1990): A framework for unsaturated soil behaviour, Géotechnique, 40 (1), 31-44.

38) Vicol, T. (1990): Comportement hydraulique et mécanique d'un limon non saturé. Application à la modélisation, $P h D$ Thesis, Ecole Nationale des Ponts et Chaussées, Paris.

39) Wheeler, S. J. (1996): Inclusion of specific water volume within an elasto-plastic model for unsaturated soil, Can. Geotech. J., 33, 42-57.

40) Wheeler, S. J. and Sivakumar, V. (1995): An elasto-plastic critical state framework for unsaturated soil, Géotechnique, 45 (1), 35-53.

41) Zakaria, I. Wheeler, S. J. and Anderson, W. F. (1995): Yielding of unsaturated compacted kaolin. Proc. Unsaturated Soils, Paris, 223-228.

42) Zerhouni, M. I. (1991): Rôle de la pression interstitielle négative dans le comportement des sols- Application aux routes, $P h D$ Thesis, Ecole Centrale Paris. 